\title{
Reação de genótipos de tomateiro às raças 2 e 3 de Fusarium oxysporum f. sp. lycopersici
}

\author{
Leonardo T Souza $^{1}$; Sami J Michereff'; Delson Laranjeira' ${ }^{1}$; Domingos EGT Andrade²; Edinardo Ferraz ${ }^{3}$; \\ Gaus SA Lima ${ }^{4}$; Ailton Reis ${ }^{5}$ \\ 'UFRPE-Depto. Agronomia, Fitossanidade, Av. Dom Manoel de Medeiros, s/n, 52171-900 Recife-PE; ${ }^{2}$ IPA-EE Itapirema, 55900-000 \\ Goiana-PE; ${ }^{3}$ IPA-EE Belém de São Francisco, 56440-000, Belém de São Francisco-PE; ${ }^{4}$ UFAL-CCA, 57100-000, Rio Largo-AL; ${ }^{5}$ Em- \\ brapa Hortaliças, 70351-970 Brasília-DF; sami@depa.ufrpe.br; degta@uol.com.br; gaus@ceca.ufal.br; ailton@cnph.embrapa.br
}

\section{RESUMO}

A murcha-de-fusário, causada por Fusarium oxysporum f. sp. lycopersici, é uma importante doença do tomateiro (Solanum lycopersicon L.) no Nordeste brasileiro. Visando selecionar genótipos com potencial de utilização no manejo da doença, foram avaliadas 60 linhagens (geração $\mathrm{F}_{7}$ ) oriundas do cruzamento entre o acesso BHRS-2,3 e a cultivar Viradoro, em relação a isolados das raças fisiológicas 2 e 3 de $F$. oxysporum f. sp. lycopersici. Os isolados foram inoculados em mudas com 21 dias de idade pelo método do corte de raízes e imersão na suspensão de conídios do patógeno. A avaliação foi realizada após 21 dias, com o auxílio de escala de notas de 1 a 5, para agrupamento dos genótipos em cinco classes de reação. A maioria dos genótipos $(73,3 \%)$ se comportou como altamente resistente ao isolado da raça 2 , enquanto $45,0 \%$ foram classificados como suscetíveis e $28,3 \%$ como altamente suscetíveis ao isolado da raça 3. Somente a linhagem L-1 apresentou reação de alta resistência aos dois isolados de ambas as raças. A estabilidade da resistência dessa linhagem foi avaliada em relação a cinco isolados de cada raça ( 2 e 3 ) do patógeno. A linhagem L-1 apresentou reação de alta resistência a todos os isolados da raça 2 , evidenciado estabilidade da resistência. No entanto, em relação aos isolados da raça 3, essa linhagem apresentou três classes de reação distintas, variando de altamente resistente a suscetível, indicando instabilidade da resistência à essa raça.

Palavras-chave: Solanum lycopersicon, murcha-de-fusário, resistência genética.

\begin{abstract}
Reaction of tomato genotypes to races 2 and 3 of Fusarium oxysporum f. sp. lycopersici

The Fusarium wilt caused by Fusarium oxysporum f. sp. lycopersici, is an important disease of tomato (Solanum lycopersicon L.) in Northeastern Brazil. In order to select genotypes with potential for use in the disease management, 60 strains were evaluated $\left(\mathrm{F}_{7}\right.$ generation) from the crossing of access BHRS-2, 3 and Viradoro cultivar in relation to isolates from the physiologic races 2 and 3 of $F$. oxysporum f. sp. lycopersici. The isolates were inoculated on 21-day old seedling using the method of cutting the roots and soaking it in the suspension of the pathogen conidia. The evaluation was carried out after 21 days, with the scale of grades ranging from 1 to 5 . The genotypes were grouped into five classes of reaction. Most genotypes (73.3\%) behaved as highly resistant to the race 2 isolate, while $45.0 \%$ were classified as susceptible and $28.3 \%$ as highly susceptible to the race 3 isolate. Only the L-1 strain showed high resistance reaction to both isolates. The stability of this line of resistance was evaluated to five isolates of each race ( 2 and 3 ). The line L-1 showed high levels of resistance to all race 2 isolates, therefore indicating high stability of resistance. However, for race 3 isolates, this strain showed three distinct classes of reaction, ranging from highly resistant to susceptible, indicating instability of resistance to this race.
\end{abstract}

Keywords: Solanum lycopersicon, Fusarium wilt, genetic resistance.

(Recebido para publicação em 30 de abril de 2009; Aceito em 3 de fevereiro de 2010) (Received on April 30, 2009; accepted on February 3, 2010)

$\mathrm{O}$ Brasil é um dos 10 maiores produtores mundiais de tomate (Solanum lycopersicon L.) (Camargo et al., 2006). Anualmente, a área cultivada com tomateiro no país supera os $50 \mathrm{mil} \mathrm{hec-}$ tares, com uma produção em torno de 3 milhões de toneladas (FNP, 2008). No estado de Pernambuco, a tomaticultura é uma importante atividade agrícola, levando grande destaque pela geração de mão-de-obra e fixação do homem no campo (Andrade \& Michereff, 2000).

A tomaticultura é bastante sensível a problemas fitossanitários. Cerca de duzentas doenças de causas bióticas e abióticas já foram relatadas afetando a tomaticultura em todo o mundo (Lopes \& Ávila, 2005). Dentre as doenças bióticas, destaca-se a murcha-de-fusário, causada pelo fungo habitante do solo Fusarium oxysporum f. sp. lycopersici (Sacc.) Snyder \& Hansen. Uma vez introduzido em áreas de cultivo, este patógeno pode permanecer viável durante anos devido a sua capacidade de produzir estruturas de resistência (clamidósporos) (Reis \& Lopes, 2007).

Em áreas infestadas por F. oxysporum f. sp. lycopersici, a doença pode se manifestar em qualquer estádio de desenvolvimento da planta (Kurozawa \& Pavan, 2005). Os sintomas mais típicos são: amarelecimento das folhas, geralmente a partir das mais velhas, queda prematura dos frutos e murcha nas horas mais quentes do dia até que a mesma se torne irreversível (Vale et al., 2004).

A espécie F. oxysporum f. sp. lycopersici é agrupada em três raças fisiológicas, conforme sua habilidade de infectar e causar doença em uma série de cultivares diferenciadoras contendo diferentes loci de resistência. No Brasil, as raças 1 e 2 encontram-se amplamente distribuídas, enquanto a raça 3 foi recentemente relatada no país em regiões mais restritas, afetando cultivos comerciais 
nos estados do Espírito Santo (Reis et al., 2005) e Rio de Janeiro (Reis \& Boiteux, 2007).

Apesar do cultivo do tomate ser uma das mais importantes atividades agrícolas no estado de Pernambuco, estudos realizados demonstraram o decréscimo da produção em áreas produtoras devido à presença da murcha-de-fusário (Andrade \& Michereff, 2000). A introdução de uma terceira raça fisiológica em áreas de cultivo no estado agravaria a situação, ocasionando resultados catastróficos para a tomaticultura regional.

Nenhuma medida de controle químico é efetiva e economicamente viável no controle da murcha-de-fusário em tomateiro (Blancard, 1996), sendo o uso de genótipos resistentes o único meio seguro e eficiente de controle da doença (Kurozawa \& Pavan, 2005). Apesar de existir uma ampla diversidade de cultivares comerciais resistentes às raças 1 e 2 de $F$. oxysporum f. sp. lycopersici no Brasil, genótipos resistentes à raça 3 ainda não estão facilmente disponíveis. Recentemente, no Brasil foram identificadas fontes de resistência múltipla às três raças de F. oxysporum f. sp. lycopersici em acessos das espécies Solanum habrochaites L., Solanum chilense L., Solanum pennellii L. e Solanum peruvianum L. (Reis et al., 2004).

Com o constante desenvolvimento de novos genótipos de tomateiro por diversos programas de melhoramento, se faz necessária a avaliação destes visando a utilização no controle genético da murcha-de-fusário. Genótipos promissores na resistência à murcha-de-fusário poderão ser utilizados extensivamente em programas de melhoramento do tomateiro, podendo auxiliar também na produção de cultivares com resistência simples ou múltipla a doenças. Desta forma, visando selecionar genótipos com potencial de utilização nos programas de melhoramento ou no manejo integrado da murcha-de-fusário, este trabalho teve como objetivos avaliar as respostas de resistência de 60 genótipos de tomateiro às raças 2 e 3 de $F$. oxysporum f. sp. lycopersici e verificar a estabilidade da resistência de genótipos promissores em relação a diferentes isolados dessas raças.

\section{MATERIAL E MÉTODOS}

A avaliação da resistência foi realizada em dois experimentos, sendo inicialmente efetuada a seleção de genótipos promissores e depois analisada a estabilidade da resistência desses genótipos. As duas etapas foram realizadas em casa de vegetação na UFRPE, em Recife-PE.

Seleção de genótipos promissores - foi realizada em casa de vegetação com temperatura ambiente variando de 22,1 a $34,4^{\circ} \mathrm{C}$, umidade relativa do ar de 62,3 a $89,6 \%$ e temperatura do solo de 21,3 a $33,5^{\circ} \mathrm{C}$. Uma coleção de 60 genótipos de tomateiro foi avaliada em relação a dois isolados de $F$. oxysporum f. sp. lycopersici, pertencentes às raças fisiológicas 2 (CMM-1252) e 3 (FUS89). A coleção de genótipos foi formada por linhagens de tomateiro desenvolvidas pela Empresa Pernambucana de Pesquisa Agropecuária (IPA), oriundas do cruzamento entre o acesso BHRS-2,3 e a cultivar Viradoro, através do método de melhoramento bulk e seleção de plantas individuais com o controle de pedigree. Todos os genótipos avaliados se encontravam na geração $\mathrm{F}_{7}$. Como controle, foram utilizados os genótipos diferenciadores das raças fisiológicas de F. oxysporum f. sp. lycopersici, incluindo Floradade (suscetível à raça 3 e resistente às raças 1 e 2), Viradoro (suscetível às raças 2 e 3) e BHRS-2,3 (resistente às raças 1, 2 e 3), bem como à cultivar Santa Clara (suscetível às raças 2 e 3), amplamente cultivada em Pernambuco até 1999, e o híbrido SM16 (resistente às raças 1 e 2 e suscetível à raça 3 ), cultivado em larga escala neste estado a partir de 2000 .

Os isolados de F. oxysporum f. sp. lycopersici foram obtidos de plantas de tomateiro das cultivares Santa Clara (CMM-1252) e Carmen (FUS-89) com sintomas de murcha-de-fusário, coletadas em Camocim de São Félix-PE (Andrade et al., 2001) e Venda Nova do Imigrante-ES (Reis et al., 2005), respectivamente. O inóculo do patógeno foi preparado em frascos de Erlenmeyer contendo $250 \mathrm{~mL}$ de meio de cultura batata-dextrose (BD) (Dhingra \& Sinclair, 1995). Após autoclavagem $\left(120^{\circ} \mathrm{C}, 30 \mathrm{~min}, 1 \mathrm{~atm}\right)$ e resfriamento $\left(25^{\circ} \mathrm{C}\right)$, em cada frasco foram colocados três discos de $5 \mathrm{~mm}$ de diâmetro de cultura do fungo, previamente cultivado em meio batata-dextrose-ágar (BDA) (Dhingra \& Sinclair, 1995), com 10 dias de idade. Após quinze dias em incubadora tipo $\mathrm{BOD}$ à temperatura de $25^{\circ} \mathrm{C}$ e luminosidade contínua, a suspensão do inóculo foi homogeneizada em agitador mecânico e filtrada em duas camadas de gaze esterilizada. Posteriormente, a contagem de microconídios nas suspensões foi realizada com o auxílio de câmara de Neubauer e a concentração do inóculo ajustada para $1 \times 10^{6}$ microconídios $\mathrm{mL}^{-1}$.

A inoculação dos isolados de $F$. oxysporum f. sp. lycopersici foi efetuada pelo método do corte de raízes (Santos, 1997) adaptado. Plantas de tomateiro, aos 21 dias após a semeadura, cultivadas sob condições de casa de vegetação em substrato Plantmax ${ }^{\circledR}$ (Eucatex Mineral Ltda., Paulínia-SP), foram removidas de bandejas tipo "plantágio", submetidas à lavagem para remoção do substrato e ao corte das raízes (cerca de $2 \mathrm{~cm}$ ) com tesoura flambada. Em seguida, as plantas foram imersas por cinco minutos na suspensão de conídios até a altura da região do colo e transplantadas para vasos plásticos $(18 \times 15 \mathrm{~cm})$ contendo solo areno-argiloso $(\mathrm{pH}=6,3$; matéria orgânica $=34,68 \mathrm{~g} \mathrm{~kg}^{-1}$; N=998 ppm; $\mathrm{P}=6 \mathrm{mg} \mathrm{dm}^{-3} ; \mathrm{K}=0,18 \mathrm{cmol}_{\mathrm{c}} \mathrm{dm}^{-3} ; \mathrm{Na}=$ $0,43 \mathrm{cmol}_{\mathrm{c}} \mathrm{dm}^{-3} ; \mathrm{Al}=0,30 \mathrm{cmol}_{\mathrm{c}} \mathrm{dm}^{-3}$; $\mathrm{Ca}+\mathrm{Mg}=0,70 \mathrm{cmol}_{\mathrm{c}} \mathrm{dm}^{-3}$ ) esterilizado em autoclave $\left(120^{\circ} \mathrm{C}, 1 \mathrm{~atm}, 60 \mathrm{~min}\right.$, dois dias consecutivos). A testemunha consistiu de plantas com raízes cortadas e imersas no referido meio de cultura, sem a presença de conídios do fungo. As plantas foram adubadas semanalmente, a partir do dia do transplantio, com $300 \mathrm{~mL}$ vaso $^{-1}$ de solução composta de: 0,02g/L de Quelatec ${ }^{\circledR}$ (B 0,65\% p/p; Fe 7,5\% p/p; S 7,5\% p/p; Mn 3,5\% p/p; Zn 0,7\% p/p; Cu 0,65\% p/p; Mo 0,3\% $\mathrm{p} / \mathrm{p}), 0,613 \mathrm{~g} \mathrm{~L}^{-1}$ de Krista-K $45^{\circledR}\left(\mathrm{N}_{2} \mathrm{O}\right.$ $\left.12 \% ; \mathrm{K}_{2} \mathrm{O} 45 \% ; \mathrm{SO}_{4} 1,2 \%\right), 1 \mathrm{~g} \mathrm{~L}^{-1}$ de Calcint ${ }^{\circledR}\left(\mathrm{NO}_{3} 14,4 \% ; \mathrm{NH}_{4} 1,1 \%\right.$; cálcio hidrossolúvel 19\%), 0,2 $\mathrm{g} \mathrm{L}^{-1} \mathrm{de}$ fosfato-monopotássico $\left(\mathrm{P}_{2} \mathrm{O}_{5} 51 \% ; \mathrm{K}_{2} \mathrm{O}\right.$ $33 \%$ ) e $0,52 \mathrm{~g} \mathrm{~L}^{-1}$ de sulfato de magnésio $\left(\mathrm{MgSO}_{4} \cdot 7 \mathrm{H}_{2} \mathrm{O} 99 \%\right)$.

Para cada raça do patógeno, o delineamento experimental foi inteiramente 
casualizado, consistindo de 65 tratamentos com quatro repetições, sendo cada repetição constituída por um vaso com quatro plantas.

A reação das plantas foi avaliada aos 21 dias após a inoculação, com escala de notas de 1 a 5 (Santos, 1997), onde: $1=$ planta sem sintomas; $2=$ planta sem sintoma de murcha e apresentando pequena descoloração vascular, $3=$ planta com sintomas de murcha e descoloração vascular; $4=$ planta com severa murcha associada com a presença de clorose e necrose foliar; $5=$ planta morta. A reação média foi calculada para cada genótipo e utilizada para agrupar os genótipos em cinco classes de reação: $1,0=$ semelhante à imune $(\mathrm{SI}) ; 1,1-2,0=$ altamente resistente $(\mathrm{AR}) ; 2,1-3,0=$ medianamente resistente $(\mathrm{MR}) ; 3,1-4,0=$ suscetível $(\mathrm{SU}) ; 4,1-5,0=$ altamente suscetível (AS) (Reis et al., 2004).

Análise da estabilidade da resistência de um genótipo promissor - foi realizada em casa de vegetação com temperatura ambiente variando de 23,6 a $35,1^{\circ} \mathrm{C}$, a umidade relativa do ar de 61,7 a $86,5 \%$ e a temperatura do solo de 22,7 a $33,9^{\circ} \mathrm{C}$. O genótipo L-1, que demonstrou reação de alta resistência (AR) às raças 2 e 3 de $F$. oxysporum $\mathrm{f}$. sp. lycopersici na seleção preliminar, juntamente com a cultivar Santa Clara e o acesso BHRS-2,3, foram avaliados em relação a cinco isolados da raça 2 (CMM-1102, CMM-1103, CMM-1106, CMM-1113 e CMM-1598) oriundos de diferentes áreas de cultivo de tomateiro em Pernambuco (Andrade et al., 2001) e cinco isolados da raça 3 (FUS-89, FUS-90, FUS-94, FUS-116 e FUS-145), cedidos pela Embrapa Hortaliças (Reis et al., 2005, 2007).

Os procedimentos de produção de mudas de tomateiro, produção do inóculo e inoculação do patógeno, adubação das plantas e avaliação da doença foram os mesmos adotados na seleção de genótipos promissores.

Para cada raça de $F$. oxysporum $\mathrm{f}$. sp. lycopersici, o delineamento experimental foi inteiramente casualizado, em arranjo fatorial $5 \times 3$, representado por cinco isolados do patógeno e três genótipos de tomateiro, com três repetições, sendo cada repetição constituída por um vaso com quatro plantas.

\section{RESULTADOS E DISCUSSÃO}

Dentre os 60 genótipos de tomateiro na geração $\mathrm{F}_{7}$ avaliados, oriundas do cruzamento entre o acesso BHRS-2,3 e a cultivar Viradoro, somente a linhagem L-2 apresentou reação semelhante à imunidade ao isolado da raça 2 (CMM1252) de F. oxysporum f. sp. lycopersici, sem a constatação de sintomas da doença. A maioria dos genótipos $(73,3 \%)$ se comportou como altamente resistente a esse isolado, enquanto $16,7 \%$ como medianamente resistente e $8,3 \%$ como altamente suscetível (Figura 1). Por outro lado, quando inoculados com o isolado da raça 3 (FUS-89) do patógeno, nenhum genótipo apresentou reação semelhante à imunidade e somente a linhagem L-1 se comportou como altamente resistente, enquanto $25,0 \%$ se comportou como medianamente resistente, $45,0 \%$ como suscetível e $28,3 \%$ como altamente suscetível (Figura 1). A linhagem L-2 que se destacou como excelente fonte de resistência à raça 2 de $F$. oxysporum f. sp. lycopersici, se comportou como medianamente resistente à raça 3 . No entanto, a linhagem L-1, que se destacou como altamente resistente em relação à raça 2 do patógeno, apresentou a mesma reação quando inoculada com o isolado da raça 3. Com base nestes resultados sugerem-se que a penetrância do gene de resistência $I-3$, na maioria dos genótipos, pode ter sido afetada devido a alguns fatores, tais como a alta concentração de inóculo utilizada (Alon et al., 1974), a severa injúria das raízes realizada na metodologia de inoculação (Juliatti et al., 1994), bem como a variabilidade genética gerada pela segregação dos materiais avaliados (Santos et al., 1993).

Em relação aos cinco genótipos de referência incluídos na avaliação, BHRS-2,3, Floradade e SM-16 comportaram-se como altamente resistentes ao isolado da raça 2 (CMM-1252), enquanto Santa Clara e Viradoro como

Tabela 1. Reação de genótipos de tomateiro a isolados das raças fisiológicas 2 e 3 de Fusarium oxysporum f. sp. lycopersici, sob condições de casa de vegetação (reaction of tomato genotypes to Fusarium oxysporum f. sp. lycopersici isolates from races 2 and 3 in greenhouse). Recife, UFRPE, 2008.

\begin{tabular}{|c|c|c|c|c|}
\hline \multirow{2}{*}{ Raça } & \multirow{2}{*}{ Isolado } & \multicolumn{3}{|c|}{ Genótipo/média $^{1}$ (reação) $^{2}$} \\
\hline & & L-1 & BHRS-2,3 & Santa Clara \\
\hline \multirow{5}{*}{ Raça 2} & CMM-1102 & $1,72^{1}(\mathrm{AR})^{2}$ & $1,75(\mathrm{AR})$ & $4,00(\mathrm{SU})$ \\
\hline & CMM-1103 & $1,58(\mathrm{AR})$ & $1,50(\mathrm{AR})$ & 2,83 (MR) \\
\hline & CMM-1106 & $1,44(\mathrm{AR})$ & $1,67(\mathrm{AR})$ & 2,25 (MR) \\
\hline & CMM-1113 & $1,33(\mathrm{AR})$ & $1,42(\mathrm{AR})$ & 2,75 (MR) \\
\hline & CMM-1598 & $1,17(\mathrm{AR})$ & $1,33(\mathrm{AR})$ & 4,42 (AS) \\
\hline \multirow{5}{*}{ Raça 3} & FUS-89 & $1,33(\mathrm{AR})$ & $1,82(\mathrm{AR})$ & $3,42(\mathrm{SU})$ \\
\hline & FUS-90 & 3,19 (SU) & $1,82(\mathrm{AR})$ & $4,10(\mathrm{AS})$ \\
\hline & FUS-94 & $2,28(\mathrm{MR})$ & $2,10(\mathrm{MR})$ & 3,74 (SU) \\
\hline & FUS-116 & $1,75(\mathrm{AR})$ & 2,19 (MR) & 4,00 (SU) \\
\hline & FUS-145 & $1,92(\mathrm{AR})$ & $2,10(\mathrm{MR})$ & 3,67 (SU) \\
\hline
\end{tabular}

${ }^{1}$ Média de reação da doença conforme escala de notas de 1 a 5 (Santos, 1997), onde: $1=$ planta sem sintomas; $2=$ planta sem sintoma de murcha e apresentando pequena descoloração vascular, $3=$ planta com sintomas de murcha e descoloração vascular; 4= planta com severa murcha associada com a presença de clorose e necrose foliar; $5=$ planta morta. Média de três repetições; ${ }^{2}$ Classe de reação da doença: $1,0=$ semelhante à imune $(\mathrm{SI}) ; 1,1-2,0=$ altamente resistente (AR); 2,1-3,0= medianamente resistente (MR); 3,1-4,0= suscetível (SU); 4,1-5,0= altamente suscetível (AS) (Reis et al., 2004) (' ${ }^{1}$ mean disease reaction class according to the disease scale from 1 to 5 (Santos, 1997), where: $1=$ symptom-free plant; $2=$ wilt symptom-free plant but presenting conspicuous vascular browning; $3=$ plant showing vascular browning and wilt symptoms; $4=$ severe wilting associated with the presence of foliar necrosis and chlorosis; $5=$ dead plant; ${ }^{2}$ Disease reaction classes: $1.0=$ similar to immune $(\mathrm{SI}) ; 1.1-2.0=$ highly resistant (HR); 2.1-3.0= moderately resistant (MR); 3.1-4.0= susceptible (SU); 4.1$5.0=$ highly susceptible). 


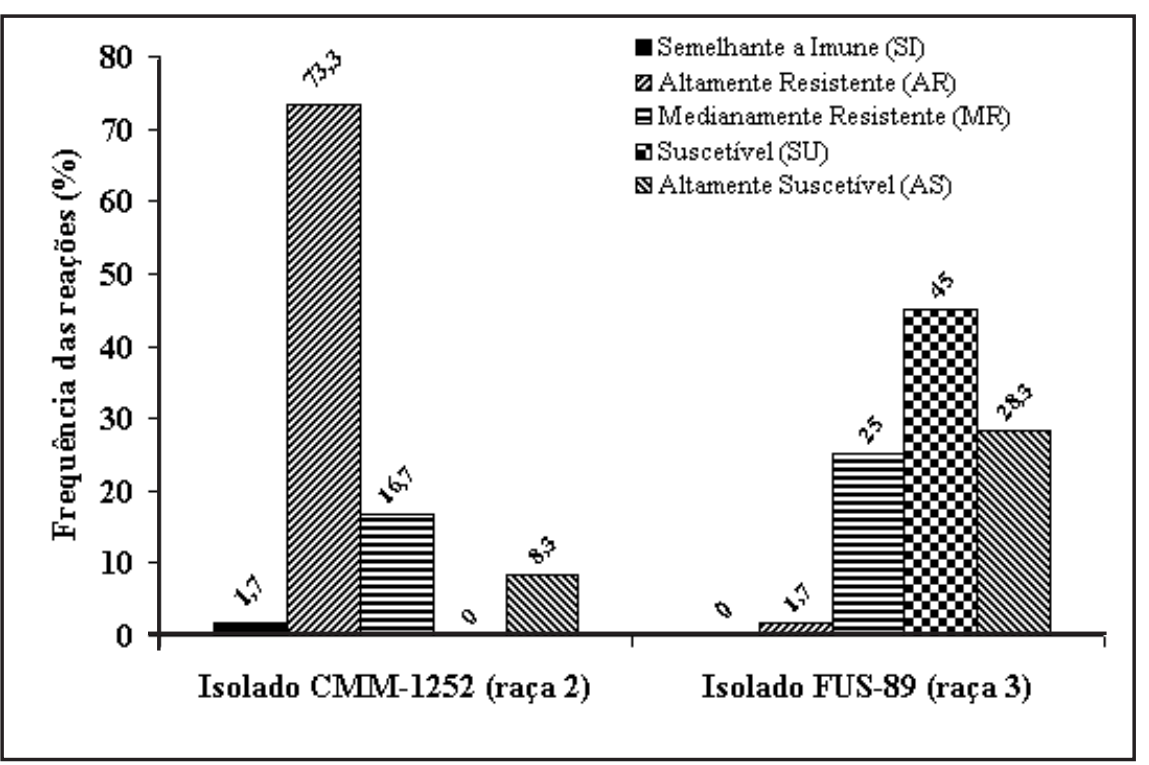

Figura 1. Frequência de classes de reação dos 60 genótipos de tomateiro a isolados das raças fisiológicas 2 e 3 de Fusarium oxysporum f. sp. lycopersici, sob condições de casa de vegetação (frequency of reaction classes of 60 tomato genotypes to Fusarium oxysporum $\mathrm{f}$. sp. lycopersici isolates from races 2 and 3 in greenhouse). Recife, UFRPE, 2008.

suscetíveis. A reação de resistência do acesso BHRS-2,3 e das cultivares SM16 e Floradade, que possuem genes de resistência à raça 2 do patógeno, assemelha-se ao constatado em outros estudos com isolados dessa raça (Juliatti et al., 1994; Andrade et al., 2000).

Quando inoculado com o isolado da raça 3 (FUS-89), o acesso BHRS2,3 se comportou como medianamente resistente, enquanto as demais cultivares Floradade, Viradoro, Santa Clara e SM16 como altamente suscetíveis. Não há relatos da ocorrência da raça 3 em cultivos de tomate no estado de Pernambuco. Considerando-se que a cultivar SM-16, avaliada no presente trabalho, foi altamente suscetível a esta raça e sendo esta vastamente cultivada por tomaticultores no estado, uma possível introdução desta terceira raça fisiológica de áreas infestadas, via semente, poderia ocasionar consequências catastróficas para a tomaticultura pernambucana. Resultados obtidos por Reis \& Boiteux (2007) reforçam a possibilidade da disseminação da raça 3 através de sementes. Estes autores relataram a ocorrência da raça 3 em municípios no estado do Rio de Janeiro, geograficamente isolados de áreas infestadas do estado do Espírito Santo, onde foi observada a primeira ocorrência da raça 3 no Brasil.

$\mathrm{Na}$ avaliação da estabilidade da resistência a isolados da raça 2 de $F$. oxysporum $\mathrm{f}$. sp. lycopersici, a linhagem L-1 e o acesso BHRS-2,3 apresentaram reações de alta resistência a todos os isolados (Tabela 1). Estes resultados sugerem que a estabilidade da resistência na linhagem L-1 em relação à raça 2 pode ter sido garantida pela herdabilidade do gene $I-2$, já que este mesmo genótipo apresenta como um dos seus genitores o acesso BHRS-2,3, possuidor dos genes $I-1, I-2$ e $I-3$, responsáveis pela resistência às três raças do patógeno (Mcgrath, 1988). Estudos realizados já identificaram reações de alta resistência à raça 2 no acesso BHRS-2,3 (Juliatti et al., 1994), bem como reações semelhantes à imunidade (Reis et al., 2004; Reis et al., 2005; Reis \& Boiteux, 2007).

A cultivar Santa Clara apresentou três classes de reação distintas em relação aos isolados da raça 2 , sendo medianamente resistente aos isolados da CMM-1103, CMM-1106 e CMM1113, suscetível ao isolado CMM-1102 1598 (Tabela 1). A reação de resistência mediana em Santa Clara para três dos cincos isolados avaliados não era esperada, já que o mesmo é desprovido do gene $I-2$, que confere a resistência à raça 2 do patógeno, como verificado por Juliatti et al (1994) e Andrade et al. (2000). Porém, ressalta-se que mesmo e altamente suscetível ao isolado CMM- dentro de uma mesma raça fisiológica pode ocorrer variabilidade quanto à agressividade entre diferentes isolados, levando desta forma a diferentes níveis de severidade da doença (Lugo \& Sanabria, 2001).

A linhagem L-1 e o acesso BHRS2,3, apesar de apresentarem reações de alta resistência a todos isolados da raça 2 , comportaram-se de forma diferenciada quando submetidos à inoculação com isolados da raça 3 (Tabela 1). A linhagem L-1 apresentou três classes de reações distintas, sendo altamente resistente aos isolados FUS-116, FUS-145 e FUS-89, medianamente resistente ao isolado FUS-94 e suscetível ao isolado FUS-90. Apesar de apresentar algumas plantas sintomáticas, não foram constatadas reações de alta suscetibilidade ou suscetibilidade no acesso BHRS2,3 em relação aos isolados da raça 3, assemelhando-se ao verificado em estudos previamente realizados no Brasil (Reis et al., 2004; Reis et al., 2005). Este acesso apresentou reação de alta resistência aos isolados FUS-89 e FUS90, e resistência mediana aos isolados FUS-145, FUS-116 e FUS-94. Reações de suscetibilidade a alta suscetibilidade foram constatadas na cultivar Santa Clara, sendo suscetível aos isolados FUS94, FUS-116, FUS-145 e FUS-89, e altamente suscetível ao isolado FUS-90 (Tabela 1). A resposta de suscetibilidade deste genótipo à raça 3 era esperada, já que o mesmo é considerado suscetível às raças 2 e 3 do patógeno (Santos et al., 1993).

Uma das hipóteses mais prováveis para a instabilidade da resistência na linhagem L-1 seria a penetrância incompleta e/ou segregação do gene $I-3$ proveniente do genitor BHRS-2,3 (Scott \& Jones, 1989). Segundo Mcgrath (1988), a possibilidade da perda de genes menores capazes de modular as respostas de resistência através de retrocruzamentos realizados pode elucidar as diferentes respostas de resistência no hospedeiro, o que poderia explicar as reações variadas de resistência e suscetibilidade na linhagem L-1. Entretanto, mais estudos devem ser realizados para a confirmação desta hipótese, como foi ressaltado por Reis et al. (2004).

Outra possível explicação para a 
reação de suscetibilidade na linhagem L-1 em relação ao isolado FUS-90 e resistência mediana ao isolado FUS-94 é a existência de diferença na agressividade entre os isolados. Conforme destacado por Schuman \& D'Arcy (2006), a classificação em raças se baseia em reação qualitativa, ou seja, capacidade ou não de causar doença, mas isolados dentro de uma mesma raça do patógeno podem variar nos níveis de agressividade, entendendo-se agressividade como uma reação quantitativa, na qual os isolados podem induzir níveis de intensidade de doença variando de baixo a elevado.

Os resultados obtidos neste trabalho evidenciam o potencial da linhagem L-1 de tomateiro como material resistente às raças fisiológicas 2 e 3 de $F$. oxysporum f. sp. lycopersici, mas se faz necessária a realização de estudo complementar em nível de campo com plantas até o estádio de frutificação para melhor compreensão da resistência genética à murcha-de-fusário.

\section{AGRADECIMENTOS}

Os autores expressam seus agradecimentos à Empresa Pernambucana de Pesquisa Agronômica (IPA, Belém de São Francisco-PE) pela doação das sementes das linhagens utilizadas nos experimentos, à Embrapa Hortaliças (Brasília-DF) pelo fornecimento dos isolados da raça 3 de $F$. oxysporum f. sp. lycopersici, e ao CNPq pela concessão das bolsas de Produtividade em Pesquisa de Sami J. Michereff, Gaus SA Lima e Ailton Reis.

\section{REFERÊNCIAS}

ALON H; KATAN J; KEDAR N. 1974. Factors affecting penetrance of resistance to Fusarium oxysporum f. sp. lycopersici in tomatoes. Phytopathology 64: 455-461.

ANDRADE DEGT; MICHEREFF SJ. 2000. Incidência da murcha-de-fusário do tomateiro no Agreste de Pernambuco e determinação do tamanho da amostra para quantificação da doença. Fitopatologia Brasileira. 25: 36-41.

ANDRADE DEGT; MARTINS RB; MICHEREFF SJ. 2000. Avaliação de cultivares de tomateiro para resistência à raça 2 de Fusarium oxysporum f. sp. lycopersici. Summa Phytopatologica 26: 161-167.

ANDRADE DEGT; MICHEREFF SJ; MENEZES M. 2001. Variabilidade de isolados de Fusarium oxysporum f. sp. lycopersici da Região Agreste de Pernambuco. Summa Phytopatologica 27: 203-207.

BLANCARD D. 1996. Enfermedades del tomate: Observar, luchar, identificar. Montfavet: INRA. $212 \mathrm{p}$

CAMARGO AMM; CAMARGO FP; ALVES HS; CAMARGO FILHO WP. 2006. Desenvolvimento do sistema agroindustrial do tomate. Informações Econômicas. 36: 53-57.

DHINGRA OD; SINCLAIR JB. 1995. Basic plant pathology methods. Boca Raton: Lewis. $434 \mathrm{p}$.

FNP. 2008. Agrianual 2008 - Anuário da agricultura brasileira. São Paulo: Instituto FNP. 532p.

JULIATTI FC; PEREIRA JJ; MALUF WR; RODRIGUES EJR; LIMA JVO. 1994. Avaliação e identificação de genótipos de tomateiro como diferenciais para as raças de Fusarium oxysporum f. sp. lycopersici. Fitopatologia Brasileira 19: 546-551.

KUROZAWA C; PAVAN MA. 2005. Doenças do tomateiro. In: KIMATI H; AMORIM L; REZENDE JAM; FILHO AB; CAMARGO LEA(eds). Manual de Fitopatologia: Doenças de plantas cultivadas. São Paulo: Agronômica Ceres. p. 607-626.

LOPES CA; ÁVILA AC. 2005. Doenças do tomateiro. Brasília: Embrapa Hortaliças. 151 p.
LUGO ZC; SANABRIANH. 2001. Características culturales y patogénicas en aislamientos de Fusarium oxysporum f. sp. lycopersici procedentes de plantaciones comerciales de tomate. Agronomia Tropical 51: 519-530.

McGRATH DJ. 1988. BHRS-2,3 Fusarium wiltresistant tomato. Hortscience 26: 1093-1094.

REIS A; GIORDANO LB; LOPES CA; BOITEUX LS. 2004. Novel sources of multiple resistance to three races of Fusarium oxysporum $\mathrm{f}$. sp. lycopersici in Lycopersicon germplasm. Crop Breeding and Applied Biotechnology 4: 495-502.

REIS A; COSTA H; BOITEUX LS; LOPES CA. 2005. First report of Fusarium oxysporum f. sp. lycopersici race 3 on tomato in Brazil. Fitopatologia Brasileira 30: 426-428.

REIS A; LOPES CA. 2007. Principais fungos de solo em hortaliças: Epidemiologia e manejo. In: ZAMBOLIM L; LOPES CA; PICANÇO MC; COSTA H (eds). Manejo integrado de doenças e pragas: Hortaliças. Viçosa: Universidade Federal de Viçosa. p. 189-224.

REIS A; BOITEUX LS. 2007. Outbreak of Fusarium oxysporum f. sp. lycopersici race 3 in commercial fresh-market tomato fields in Rio de Janeiro State, Brazil. Horticultura Brasileira 25: 451-454.

SANTOS JRM; LOPES CA; LIMA BJC. 1993. Cultivares de tomateiro diferenciadoras de raças de Fusarium oxysporum f. sp. lycopersici. Horticultura Brasileira 11: 27-29.

SANTOS JRM. 1997. Methodology for screening tomato for Fusarium wilt, Verticilium wilt, Gray leaf spot, Early blight and Septoria leaf spot. In: INTERNATIONAL SYMPOSIUM ON TROPICAL TOMATO DISEASES, 1. Anais... Recife: IPA. p. 164-166.

SCHUMAN GL; D'ARCY CJ. 2006. Essential plant pathology. St. Paul: APS Press. 338p.

SCOTT JW; JONES JP. 1989. Monogenic resistance in tomato to Fusarium oxysporum $\mathrm{f}$. sp. lycopersici race 3. Euphytica 40: 43-53.

VALE FXR; ZAMBOLIM L; ZAMBOLIM EM; ALVARENGA MAR. 2004. Doenças fungicas. In: ALVARENGA (ed). Tomate: Produção em campo, em casa-de-vegetação e em hidroponia. Lavras: UFLA. p. 218-258. 